\title{
El cine en el currículum de Educación Primaria. Propuesta metodológica para educar en valores y formar a espectadores críticos
}

\author{
The cinema in the curriculum of Primary Education. Methodological \\ proporsal for values education and training critical viewers
}

\author{
Eugenia Paredes Fernández (Universidad de Sevilla) \\ http://dx.doi.org/10.12795/AdMIRA.2010.01.04
}

Resumen: Esta investigación trata de demostrar el importante elemento educativo que supone la inclusión del cine en las escuelas como fórmula para educar en valores y formar a espectadores críticos. Para conseguir este propósito se ha creado una metodología didáctica que se aplica a películas españolas de animación y cuyos resultados nos permiten reconocer que este medio es un elemento capaz de configurar mentalidades y ofrecer modelos de actuación positiva, generando mitos y valores sociales entre los receptores más jóvenes. La incorporación de la educación en materia cinematográfica en las escuelas no sólo persigue enseñar a ver las obras sino también aprender a pensar lo que se ve. Se trataría de capacitar al menor para que asuma como propias las enseñanzas aprendidas a través de métodos audiovisuales, en definitiva, un paso más dentro del proceso de alfabetización audiovisual que muchos investigadores consideramos necesario dentro de la escuela primaria para la formación social y humana del menor, y su evolución futura.

Palabras Claves: cine, animación, educación, valores, escuela, infancia, alfabetización mediática.

\begin{abstract}
This research tries to demonstrate the important educational element that supposes the incorporation of the cinema in the schools as a formula to educate in values and to train critical spectators. To obtain this purpose a didactic methodology has been created. It is applied to Spanish movies of animation and its results allow us to admit that this way is an element to form mentalities and to offer models of positive action, generating myths and social values among the children. The incorporation of education about cinematographic in the schools not only tries to teach how to see the films but also to learn to think what one sees. It would be a matter of qualifying children to assume like own the educations learned through audio-visual methods. Definitively, it is another step in the process of audio-visual literacy that many researchers consider to be necessary in the primary school for the social and human training of children and their future evolution.
\end{abstract}

Keywords: Cinema, animation, education, values, school, infancy, media literacy.

\section{Introducción}

Importantes estudios han demostrado ampliamente que el cine, y los mass media en general, son excelentes medios para educar a los menores y transmitir emociones ya que 
a través de ellos se representan los valores y contravalores de la sociedad, al mismo tiempo que ayudan al menor a desvelar aspiraciones y sentimientos que tenía ocultos en su interior. Y aún más, los conflictos que se presentan y la forma de solucionarlos o adaptarse a ellos son enseñanzas que emanan de esa confluencia entre vida real e imaginada. Centrándonos en el cine, como material educativo de primer nivel, éste puede provocar cambios en sus conductas para que sean responsables y conscientes de sus actos; que se interesen por los demás y lo demuestren; que tengan ideales nobles; que sean realistas, resistentes a las desilusiones, flexibles y capaces de adaptarse a las situaciones que les quedan por vivir; que sean capaces de amar de forma generosa (Prats, 2005).

Pero todo lo enumerado anteriormente se quedaría en buenos propósitos, ciertamente difíciles de alcanzar, si no se produce una remodelación del sistema educativo actual, empezando por las leyes que lo rigen, continuando con las mejoras tanto en infraestructura como en los mecanismos de formación del profesorado y finalizando con el apoyo expreso hacia estos nuevos métodos de enseñanza desde el ámbito familiar en el que se mueve el menor. Para alcanzar estos propósitos, que deben incluir no sólo a la educación cinematográfica sino a cualquier otra educación en medios de comunicación y nuevas tecnologías, la escuela debe adaptarse a los nuevos modos de aprendizaje y reelaborar sus proyectos educativos haciéndolos más cercanos a la realidad que le toca vivir al alumno.”Estamos viviendo una transformación tan seria de la educación que los pilares que sostenían su autonomía escolar y sobre la cual se fundaba su influencia social parecen derrumbarse a ojos vista. En cierto sentido la sociedad se está quedando sin aulas, es decir, sin esos espacios cerrados, controlados y reservados en los que el saber fluía verticalmente del maestro a los alumnos. Y es así porque aunque, en términos globales, el número de éstas puede ir aumentando, su peso específico en la sociedad no deja de disminuir desde hace décadas” (Pérez Tornero, 2000: 45).

Siguiendo esta línea de investigación, hay voces de alarma que de manera insistente previenen de la existencia de un desfase entre lo que el alumno demanda y lo que el centro educativo puede ofrecer. Esto genera una conciencia de continua y perpetua crisis en la educación que dura ya varios siglos y cuyos motivos describe ampliamente Savater en su obra El valor de educar (2004).

La investigación, trata de demostrar de forma didáctica, que el panorama no puede ser tan negativo como muchos quieren hacer entender y que la escuela, con sus virtudes y 
defectos, puede ser un perfecto agente transmisor de valores a través de los medios de comunicación. Por ello, el estudio inicial, partiendo de un análisis detallado de distintas obras de animación españolas, de las que se realiza una propuesta metodológica, tiene como finalidad introducirlas como enseñanza curricular en las escuelas. En el artículo y a modo de ejemplo, se presenta la ficha de actividades elaborada para trabajar en clase la obra El lince perdido (2008).

\section{El cine como instrumento educativo en una escuela cambiante}

La sociedad actual se enfrenta a un problema fundamental que tiene como protagonistas a los niños desde muy temprana edad pero que se va agravando durante su adolescencia, y que consiste en la ausencia parcial o casi total de determinados valores humanos y sociales que son necesarios para una convivencia pacífica. Esto provoca un gran malestar en padres, educadores y la sociedad en general que no sabe como afrontar y solucionar este problema.

Algunos organismos nacionales y autonómicos entre los que se encuentran el Ministerio de Educación ${ }^{1}$, el Gobierno de Cantabria ${ }^{2}$, la Comunidad de Castilla-La Mancha ${ }^{3}$, la Junta de Extremadura ${ }^{4}$ o la Junta de Andalucía, previendo quizás la magnitud de la situación y teniendo en cuenta el aumento considerable de los conflictos generados por menores, están realizado políticas de educación y fomento de los valores en todos los niveles educativos.

En el caso andaluz la Junta ha creado una Guía de Educación en Valores (2001) en la que se definen los valores considerados fundamentales para la formación humana y social del menor, y de necesaria aplicación en los diseños curriculares educativos de la Comunidad Autónoma. Dichos valores se expresan en los siguientes puntos:

- Educación para la salud:

o Sexualidad y experiencias tempranas sexuales

o Alimentación

- Educación ambiental:

o El ciclo de los materiales y las basuras

o El medio ambiente urbano 
- Coeducación

o Los roles

o Violencia de género

- Educación para la paz y la interculturalidad

o Resolución de conflictos de forma no violenta

o Diversidad cultural

- Educación para la participación activa en la sociedad y para la vida en comunidad

o Participación activa

o La vida en comunidad

- Educación para el desarrollo y la cooperación

o Desarrollo en el tercer y cuarto mundo

o Cooperación

- Educación vial

o La normas y la educación vial

o Comportamientos en la educación vial

$\mathrm{Y}$ es que el fomento de determinados valores debe ser una prioridad educativa ya que están presentes en una persona casi desde los inicios de su vida. Al principio los menores llegan a ellos a través de la imitación del comportamiento de los mayores y poco a poco, conforme van creciendo, se van "adscribiendo" a unos u otros y los van haciendo suyos.

Tomando como ejemplo esta guía de valores creada por la Junta de Andalucía, se analizaron diez ${ }^{5}$ películas de animación españolas rodadas entre el año 2000 y el 2008, y se estableció, tal y como puede verse en las conclusiones, una distribución de los valores presentes en las obras estudiadas teniendo como referente la guía anteriormente citada.

Partiendo de la premisa de que en esta etapa los menores reciben influencias de cuatro agentes socializadores como son la familia, la escuela, el grupo de amistades y los medios de comunicación de masas. Es importante incidir en que el desarrollo de las 
nuevas tecnologías de la información y comunicación, unido a los cambios que se están produciendo dentro del ámbito familiar y escolar, está configurando un nuevo espacio social donde las modificaciones son muy rápidas y en muchos casos resulta muy difícil para el menor adaptarse a ellas. La escuela, como lugar de conocimiento y educación, no puede permanecer al margen de los numerosos problemas que estas transformaciones están produciendo. "Es necesario formar al niño, al adolescente y al joven de la actual sociedad, que se halla en crecimiento integral y preparándose para su prolongado rito de entrada en el universo de los adultos (de la toma de decisiones y la responsabilidad), en comprender y analizar uno de los elementos que más importancia tendrá en el transcurso de su vida, la comunicación, cuya forma y características se encuentran paulatinamente transformadas debido a la irrupción de nuevos instrumentos” (Gómez Galán, 2003: 28).

La escuela como institución, en este último cuarto de siglo, tiene un menor papel socializador y formador sobre la infancia y la juventud, teniendo que compartirlo en estos momentos con los mass media. Y es previsible que si en los próximos años no renueva profundamente sus metas, sus contenidos y su metodología, entrará en una profunda crisis. La búsqueda de soluciones a este problema consiste en reflexionar y discutir sobre la formación cultural que se quiere potenciar en los alumnos, cómo integrar esa cultura mediática en las escuelas, cómo transformar a los medios de comunicación en objeto de estudio y análisis curricular, y cómo lograr que los estudiantes transfieran este conocimiento a su vida cotidiana.

Por ello la necesidad de incorporar al currículum una educación para los medios de comunicación debiera ser una tarea urgente no sólo con la intencionalidad de alfabetizar al alumnado en el dominio de los códigos y lenguajes expresivos de estos medios, sino y sobre todo por una razón más poderosa: para formar ciudadanos que sepan desenvolverse inteligentemente en un contexto social mediático.

De forma similar A. Pérez sugiere que la escuela debe replantear sus funciones ante el nuevo contexto social, que entre otros rasgos, se caracteriza por el predominio cada vez más acentuado de la cultura audiovisual. Por ello afirma que: “Más que transmitir información, la función educativa de la escuela contemporánea debe orientarse a provocar la organización racional de una información fragmentaria recibida y la reconstrucción de las preconcepciones acríticas, formadas por la presión reproductora 
del contexto social, a través de mecanismos y medios de comunicación cada día más poderosos y de influencia más sutil” (1992: 32).

Ésta tendría que ser una de las funciones sociales claves de la escuela en este final de siglo: ayudar y capacitar al alumnado a tomar conciencia del papel de los medios en nuestra vida social; a que conozcan los mecanismos técnicos y de simbología a través de los cuales los medios provocan la seducción del espectador; a promover criterios de valor que permitan a los alumnos discriminar y seleccionar aquellos productos de mayor calidad cultural; sacar a la luz los intereses económicos, políticos e ideológicos que están detrás de toda empresa y producto mediático.

En definitiva, el papel de la escuela, pasaría por ayudar a formar ciudadanos más cultos, responsables y críticos ya que el conocimiento (en este caso sobre los mecanismos de seducción y concienciación de los mass media y las nuevas tecnologías de la comunicación) es una condición necesaria para el ejercicio consciente de la libertad individual y para el desarrollo pleno de la democracia.

El hecho de que algunas de las historias que llegan a través del cine tengan tanto poder e influencia sobre el público receptor hace pensar que no se trata sólo de un mero entretenimiento sino que es necesario tenerlo en cuenta como objeto de estudio académico por parte de investigadores y docentes. Es un medio capaz de configurar mentalidades e influir creando paradigmas de actuación, sobre todo en el público infantil que es el que nos ocupa. Y su importancia radica en que los mensajes contenidos pueden modificar el comportamiento de estos receptores de forma positiva o negativa ya que ejercen un alto poder de persuasión, debido principalmente a la escasez de la edad del receptor y a su falta de madurez personal (De la Torre et al., 2005: 3753).

Entendemos que una forma eficaz de potenciar la educación en valores entre los niños y llevarlos a la práctica es hacerlo con un canal de transmisión cercano y atractivo para ellos como es el cine, que está presente en su vida diaria y que debido a esta cercanía se considera, de forma errónea, que no necesita de ninguna formación ni preparación previa para su comprensión. Se pretende demostrar la falsedad de esta afirmación, defendiendo que es el mismo individuo el que construye de forma activa su propia escala de valores a través de un proceso de razonamiento personal. Pero que para ello necesita que las personas, y los medios que interactúan con él y lo socializan, le aporten 
su propia escala de valores. Al final, sin embargo, será el menor el que decidirá las enseñanzas que asumirá como propias y las que no.

Está claro que la educación debe buscar la formación del individuo en su totalidad y fomentar el nacimiento de nuevos valores. Como anteriormente explicaba, entre los agentes socializadores que conforman al ser humano están los medios de comunicación y son junto con la familia, los amigos y la escuela los que deben provocar la reflexión, el descubrimiento, la incorporación y la realización de valores en el menor (Casals, 2005: 25). Y una forma eficaz de hacerlo es a través de la educación mediática.

Existe una abundante bibliografía en torno al concepto de alfabetización mediática, incluso se va mucho más lejos al considerar la necesidad de una alfabetización hipermediática ${ }^{6}$ donde se traten aspectos como educomunicación, recepción crítica, educación para los medios, educación con los medios, educación a través de los medios y educación en medios. Estas reflexiones teóricas y críticas definen la estrecha relación existente entre los conceptos de comunicación y educación, y en la mayoría de los casos sostienen que ambos son, en realidad, un mismo término en la actual sociedad de la información (Fontcuberta, 2001; Kaplún, 1998).

Fontcuberta plantea la necesidad de un replanteamiento general de los conceptos y métodos que se utilizan en la relación comunicación-educación, tanto desde una perspectiva comunicativa, como educativa. Los nuevos tiempos exigen que el aprendizaje se aproxime cada vez más tanto a la comunicación como al estudio de las emociones y sentimientos del menor. No olvidemos que el proceso educativo no es sólo un procedimiento ligado a la razón y que los componentes emotivos tienen una trascendencia fundamental. Señala que "un alumno alfabetizado en el mundo de las emociones es un alumno mucho más capaz de efectuar una lectura crítica del mensaje que está recibiendo de los medios” (2001: 71). Es por ello, que los medios son una herramienta fundamental para la alfabetización emocional y, por ende, también para la alfabetización sobre y para los medios.

\section{Metodología}

Con el fin de delimitar el objeto de estudio y convertir lo que podría ser una amplia investigación en algo finito y abarcable, el proyecto centró su estudio en los valores presentes en largometrajes de animación infantil producidos en España, entendiendo 
con esto los que se han realizado con parte de presupuesto español o por productoras de nuestro país.

En concreto se desarrolla una metodología didáctica destinada a niños de 6 a 10 años en la que de forma sencilla y divertida para ellos se introducirá el cine formativo en las aulas y se les educará en aspectos vitales para su desarrollo como son la reflexión, el análisis, la crítica, la valoración y el trabajo en equipo. Se elige esta edad como la apropiada para ir introduciendo el cine en sus vidas porque el niño, en su proceso de socialización, ya comienza a estar capacitado para diferenciar nociones de duración, intensidad y ritmo. Comprende y puede interpretar los movimientos, su conciencia del mundo exterior aumenta poco a poco, sitúa a los personajes de las obras y coordina diferentes acciones. Sabe diferenciar el objeto del sujeto y comienza a discernir y a reconocer puntos de vista propios y ajenos. Aunque esta evolución no es homogénea, ya que el desarrollo del menor también atiende a factores medioambientales y personales del individuo (Serra, 1970: 27-35), es el momento perfecto para que hagan suyos determinados principios y valores.

Como en todo acto didáctico preocupan tanto los procesos como los resultados. Así, importa que el alumno desarrolle sus capacidades de redacción, de investigación, de búsqueda, de creación, de análisis o de síntesis. Además sería conveniente que a lo anterior se una la transmisión de unos conocimientos técnicos básicos sobre la realización de la obra y las fases de su proceso creativo. El cine de animación en general, y todos los medios de comunicación de masas, poseen sistemas, lenguajes y estructuras que permiten por sus propias características ser vehículos transmisores de recursos y posibilidades para poder establecer en el aula estrategias que posibiliten la transversalidad $^{7}$ que tanto se busca en la educación actual.

En este caso, se ha considerado que una película es rica en contenidos cuando en ella se aplican conocimientos, habilidades y comportamientos de lengua, ciencias, plástica y dibujo, estética, composición de espacios y de tiempos, técnicas de investigación y relación con el entorno, historia y política, etc. Y todo ello a partir de actividades de interrelación personal y en grupo. Además de formar a los menores aportándoles modelos de actuación y valores a seguir, las actividades propuestas van a potenciar e inciden especialmente en la búsqueda de información, planificación, organización y acercamiento a la realidad social del alumno. 
Al tratarse de un proyecto educativo y tener como meta fundamental la educación en valores, el trabajo pretende crear una fórmula de intervención sobre los menores utilizando para ello procedimientos que deben ser rigurosos, eficaces y fáciles de transmitir.

"La intervención no podrá ser eficaz si no cuenta con un escrupuloso y amplio conocimiento de los fenómenos a los que se dirige. Conocimiento que, a su vez, proporciona aquellas directrices fundamentales a través de las cuales estructurar adecuadamente la propia intervención, evaluarla y convertirla, de forma recursiva, en un proceso investigador. De ahí que la intervención vaya de la mano de la investigación, es más, la intervención se convierta también en investigación” (López y Scandroglio, 2007: 558).

Y efectivamente la investigación y la intervención no pueden separarse la una de la otra, como explican estos autores, ya que se complementan y una da sentido a la otra y viceversa. La investigación ayuda a conocer los fenómenos sociales sobre los que vamos a actuar y sus antecedentes, y cuando conocemos estos datos nos es más fácil actuar sobre ellos provocando cambios y mejoras sociales (intervención).

El hecho de utilizar en este caso, casi con exclusividad, un enfoque teórico cualitativo se debe a que la intención es explorar situaciones, describir los hechos explorados y descubrir relaciones entre los hechos y los comportamientos del menor. Se va a enfatizar la interpretación sobre la medición y se tratara de dar sentido a la investigación relacionándola con las influencias sociales, culturales e históricas de los propios individuos y sus interpretaciones del mundo.

La delimitación del campo de investigación a la animación infantil española se debe a varias razones:

- Es necesaria una importante campaña de imagen que mejore sensiblemente el concepto que se tiene del cine de animación español. Este género sigue siendo un gran desconocido para los espectadores, sobre todo para los adultos, a pesar del aumento de la producción y la distribución del cine animado en nuestro país. Su difusión es escasa, su seguimiento es reducido por parte de crítica y público, y sus resultados económicos suelen ser bastante dispares.

- Es un cine que debe ser tenido muy en cuenta en actividades educativas ya que transmite valores cercanos, analiza las costumbres y formas de vida del país, expone las 
características culturales de los territorios y al mismo tiempo los elementos diferenciadores que enriquecen la multiculturalidad.

- Realizando un sondeo a los menores sobre un personaje, un título o una trama de una película española muy pocos darían una respuesta acertada, aunque sean cerca de un centenar los títulos estrenados por las empresas de animación desde 1945 hasta nuestros días. Y es que se trata de un género muy poco conocido debido principalmente a que no hay una producción fluida ni con una calidad necesaria que nos permita sospechar de la existencia de una completa infraestructura para su desarrollo.

- Por último y un motivo más para incidir en el estudio de la animación española es que debido principalmente a los grandes esfuerzos que se hacen en marketing y publicidad, el cine de animación norteamericano- Disney, Pixar,...- parece ser el único que existe, tanto para la crítica como para los investigadores.

Para introducir a los menores más fácilmente en la metodología a seguir se ha tenido en cuenta que las películas sean entretenidas, que tengan los ingredientes necesarios en dinamismo, color, música, cambios de acción y de estímulos suficientes para atraer a los más pequeños. Que fomenten la imaginación y traten los temas con la libertad que no puede alcanzarse en la imagen real, permitiéndose rarezas y excentricidades. Son obras donde el color, los escenarios y las formas caricaturescas tienen más parecido con la propia forma de expresión pictórica de los niños, haciendo posible relatar cualquier tipo de historia en donde objetos, figuras, animales, plantas o signos se mueven expresándose como una persona.

Considerando que el despegue de este cine en nuestro país se produce con la llegada del siglo XXI, todas las películas analizadas en el proyecto se encuadran desde esta fecha y hasta nuestros días. Son largometrajes dirigidos a un público infantil y con una calificación de apta para todos los públicos. Además de lo expuesto, se han seleccionado obras basadas en los siguientes criterios:

- Atractivas a los ojos de los escolares.

- Adecuadas al nivel educativo del alumnado.

- Transmisoras de valores cívicos.

- Enriquecedoras desde el punto de vista personal.

- Adecuadas para realizar una reflexión y el análisis intelectual. 
- Motivadoras.

El modelo de análisis se ha pretendido sencillo y práctico ya que a lo que se aspira inicialmente es a realizar un esquema general de los temas, valores y contravalores utilizados por la animación española para crear sus obras. Hay un primer apartado en el que al cartel promocional de cada film, para que sea rápidamente identificable y a su ficha técnica donde se presentan los personajes más importantes de la obra, le sigue una sinopsis del argumento con las distintas tramas. El apartado “otros datos de interés” informa de elementos de la obra que son importantes reseñar como la recaudación obtenida, el número de espectadores alcanzados, los premios conseguidos o las críticas publicadas.

Todo lo anterior nos ha permitido conocer con exactitud el tema principal y los posibles subtemas que se plantean, y esto nos ayuda a adentrarnos en la segunda parte de la ficha consistente en una breve descripción de los valores positivos y negativos que se han identificado en la obra, y un análisis de los elementos educativos más importantes del film. La tercera y última parte es una propuesta metodológica de intervención educativa para trabajar en el aula con los alumnos.

A través de estas actividades creativas se busca que los menores reflexionen y opinen sobre lo que han visto con el fin de que sean ellos mismos los que lleguen con su trabajo a la conclusión de las enseñanzas que transmite la obra.

Al tratarse de un estudio de valores también se ha tenido en cuenta la frase más significativa que dentro del film resume los elementos positivos que se quieren resaltar. Se ha seguido una metodología de análisis narrativo propuesta por distintos autores como Casetti y Di Chio (Cómo de comenta un film) o Ramón Carmona (Cómo se comenta un texto fílmico) y así de cada obra se ha realizado una ficha de análisis descriptiva que es igual para todos los films propuestos y una valoración final que se ofrece a modo de conclusión del trabajo desde el punto de vista estudiado, la educación en valores.

Todos los análisis implican los actos de reconocimiento y comprensión: reconocimiento al analizar los elementos individuales que aparecen en la pantalla (personajes, frases, sonidos,...) y comprensión al relacionar estas individualidades y darles un sentido completo. Para conseguir nuestro propósito se han descompuesto las distintas unidades 
que conforman cada película para después recomponerla dándole un sentido a la investigación.

Las pretensiones de la estrategia metodológica propuesta se pueden resumir como sigue:

- Sensibilización: Se estimula al alumno a utilizar todos sus sentidos para explorar la obra y expresar sus sentimientos, ideas y opiniones con respecto a ésta.

- $\quad$ El proceso de aprendizaje es vivencial.

- Enfoque creativo: Las actividades creativas son utilizadas para que los participantes expresen sus pensamientos y sentimientos.

- El juego y la diversión como recursos didácticos: Las experiencias divertidas y agradables tienen un mayor impacto que las formales y aburridas.

- El guía es un facilitador del proceso educativo. Promueve el desarrollo personal y la toma de conciencia de los participantes estimulando su autoestima.

- Se fomenta el trabajo cooperativo al eliminar la competencia y la comparación. Se favorece la integración de la comunicación y el uso de las habilidades individuales y grupales en la resolución de problemas y en el asumir retos.

Por último, y teniendo el docente como referencia para sus clases las fichas de análisis que se recogen tras cada obra, la propuesta de estudio a seguir en el aula sería la siguiente:

1. Presentación de la película

2. Ficha técnica y artística

3. Sinopsis y datos de interés

4. Visionado de la obra

5. Identificar lo que sucede

6. Análisis de los personajes, los escenarios y el tiempo

7. Educación en valores

8. Actividades de apoyo

9. Conclusiones 


\section{Actividad de apoyo}

\section{El Lince Perdido}

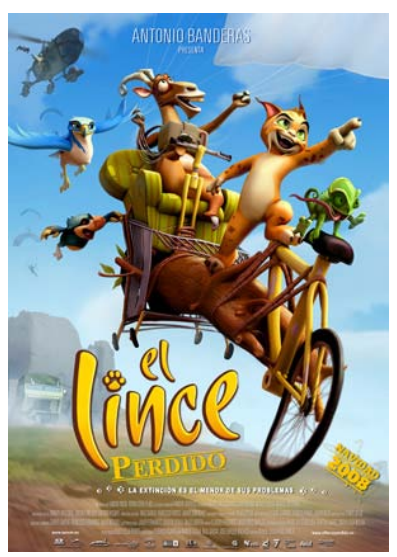

"Sonríe que mañana puede ser peor"

Félix

\section{FiCHA ARTístico-TÉCNICA}

Dirección: Raúl García y Manuel Sicilia

País: España

Año: 2008

Duración: 97 minutos

Género: Animación/ Comedia

Personajes: - Félix

- Gus

- Beea

- Astarté

- Rupert

- Noé

- Newmann

Guión: Manuel Sicilia, Raúl García y José Enrique Machuca

Producción: Antonio Banderas, Manuel Sicilia, Marcelino Almansa, Juan Molina y

Manuel Cristóbal

Productora: Kandor Graphics, Green Moon y Perro Verde Films

Música: Sergio de la Puente

Montaje: Claudio Hernández y Nacho Ruiz Capillas

Calificación: Todos los públicos

\section{SINOPSIS}

Félix es un lince que cree que por culpa de su mala suerte su especie está en peligro de extinción. Tras pasar por varios centros de acogida de animales llega a El Acebuche (Parque Natural de Doñana) y allí descubre que se están produciendo extrañas desapariciones de animales en la zona. Noé, un millonario preocupado por los problemas ambientales, organiza un plan para proteger a los animales en peligro de extinción cazando una pareja de cada especie y construyendo un refugio secreto en una isla en el que albergarlas. Para conseguir su propósito contrata a Newmann, un cazador encargado de encontrar a los animales pero Félix, Beea, Astarté, Gus,...y otros intentarán impedir sus planes y salvar a Lincesa que ha sido secuestrada. 


\section{OTROS DATOS DE INTERÉS}

- Su presupuesto ha sido de 4,5 millones de euros.

- El nombre del protagonista, Félix, está puesto en honor al defensor de la naturaleza Félix Rodríguez de la Fuente. Un 20 por ciento de los beneficios obtenidos con la película irán destinados a financiar proyectos medioambientales.

- Premios:

- Goya 2009 a la mejor película de animación española.

- Mejor película 2008 en el Festival Internacional Animadrid.

- Mención especial en el Festival Internacional Animador 2008.

- Paisajes como el parque de Doñana, Sierra Nevada, Despeñaperros, la Sierra de Cazorla, el desierto de Tabernas o las playas de Monsul y Bolonia son reconocibles por el espectador.

- Se han generado 150.000 las imágenes por ordenador, en las que han trabajado 40 profesionales de la animación durante ocho meses.

- Críticas:

“Cuando el talento (y no el dinero) dibuja las películas de animación. Con un pie puesto en una animación de calidad y otro en un estupendo guión, una conjunción muy poco frecuente en los dibujos animados españoles.” (G. Belinchón: El País).

"En El Lince Perdido, García y Manuel Sicilia parecen haber aplicado las reglas de oro del ideario Disney (personajes con alma, sentido del espectáculo, dinamismo a ultranza) en un trabajo que no solo pulveriza todo prejuicio sobre el carácter posibilista de la animación española, sino que posee fuerza y carisma para defenderse (y gustar) fuera de nuestro mercado." (Jordi Costa: Fotogramas)

\section{TEMAS, VALORES, CONTRAVALORES Y EDUCACIÓN}

\section{TEMAS}

- Protección del medio ambiente.

- Valor de la amistad

- Derecho a la libertad

- Ayuda desinteresada

VALORES

- Amor

- Amistad

- Compañerismo

- Libertad

- Protección

CONTRAVALORES

- Avaricia

Esta Película edUCA EN

- El derecho a la libertad de humanos y animales.

- La protección del medio ambiente, el desarrollo sostenible y el reciclaje.

- Aceptar la colaboración y el consejo de los demás para solucionar tus problemas.

- Justicia y saber perdonar. 


\section{ACTIVIDADES}

1. El educador utiliza la página web oficial de la película (http://www.ellinceperdido.com/) para enseñar a los alumnos el uso de de Internet y cómo se navega por la red.

2. En la película se realizan continuas alusiones a Félix Rodríguez de la Fuente y a su obra. El educador explicar en clase quien fue este naturalista y comunicador, muestra algunos de sus documentales e informa sobre las acciones medioambientales llevadas a cabo actualmente por su fundación (http://www.felixrodriguezdelafuente.com/).

3. La clase visita un centro de reciclaje de la ciudad y pone en práctica tanto en clase como en casa todo lo aprendido. Con ayuda del educador, los alumnos crean su propio centro de reciclaje en la escuela colocando distintos recipientes de colores en el aula para que se depositen allí los materiales de desecho:

o Azul: Papel, cartulinas, etc.

o Verde: Vidrio

o Negro: Pilas

o Amarillo: tetra-bricks, latas y plásticos

o Naranja: Residuos orgánicos

4. El alumno recuerda los distintos animales que aparecen en la película, elige a uno de ellos y con la ayuda de sus padres realiza una redacción con las características físicas y la forma de vida del animal seleccionado.

5. ¿Qué significa estar en peligro de extinción?, ¿cuántos animales se encuentran en esta situación?, ¿qué harías para impedirlo? Crea unos murales, que después se puedan colocar por la clase con los animales en peligro de extinción y su forma de vida.

6. Analiza en clase las siguientes frases y decide cual es para ti la más importante:

o “¿Qué sentido tiene vivir si no tienes libertad?” Lincesa

o “¿Qué sentido tiene la libertad si no estás vivo?” Noé

7. En la obra hay varias localizaciones que son muy reconocidas, intenta realizar un mapa con el recorrido de los animales:

o Desierto de Tabernas

o Parque Natural de Doñana

o Sierra Nevada

o Despeñaperros

o Sierra de Cazorla

o Playa de Bolonia

8. El educador explica en clase qué es un parque eólico y cómo se obtiene la energía.

9. La historia de Noé y su intención de crear un refugio para animales está ya recogida en el Antiguo Testamento (Génesis capítulo 6 al 9). El profesor cuenta en clase esta historia para analizar las semejanzas y diferencias con respecto a la película. La clase realiza su propia Arca y recoge en ella los animales que considera más importantes. Después cada alumno discute su elección con el resto de la clase. 


\section{Conclusiones}

La sociedad utiliza el cine como puerta de entrada a sus fantasías, a unas situaciones que probablemente nunca experimenten pero de las que son partícipes durante un periodo de tiempo, concretamente hasta el final de la emisión. Pero en los niños el final de su mundo imaginario no necesariamente se corresponde con el final del film, a veces llega mucho más allá y estas fantasías se trasladan a su vida diaria y a su cotidianeidad. Es una ventana a un mundo nuevo que debe servir a padres y educadores para "preparar a los niños y a los jóvenes para el mundo en el que han de vivir, de hacer presente en la educación casi todo lo que existe en ese mundo a través de su representación cinematográfica; de servirse del cine para abordar de una forma viva la educación en valores; y, sobre todo, de aprovechar el cine, por su conexión con la emoción, con el sentimiento, con la belleza, con el arte, para no olvidar que la educación ha de ser integral, que la meta de la educación es la persona total” (Pereira, 2005: 20).

El cine de animación en general no disfruta de muy buena acogida entre los profesionales de la educación. Existe una extensa línea de trabajo sobre este tema que se puede calificar como crítica y que se ha centrado principalmente en denunciar en las películas la presencia de roles y la tendencia a fomentar la violencia estimulando conductas agresivas. De este modo se han evitado otros aspectos beneficiosos de este cine como es su potencialidad para educar. En general, se le censura que fundamente su humor en la agresión y la violencia gratuita, fomentando actitudes de desprecio al otro, donde la resolución de conflictos se desenvuelve más desde el recurso a la fuerza bruta, o con el empleo de poderes más o menos ocultos, por encima del razonamiento y la búsqueda de consensos dialogados. Los detractores más críticos no dudan en llegar a denunciar incluso que se trata de un cine de escaso nivel intelectual, que empobrece el lenguaje del menor y su pensamiento, deformando los hábitos de lectura a la vez que promueve unas ideas simplistas donde se esquematiza la vida social y humana.

Indudablemente el cine de animación necesita una importante renovación en el futuro, debe adaptarse a la sociedad del momento y cuidar los diálogos y las escenas para evitar que siga siendo un arte poco estimado y relegado a segundo plano dentro de la cinematografía española. Ésta suele estar vacía de producciones animadas durante varios meses, e incluso años, debido principalmente a que las ayudas al cine de animación son muy escasas y eso repercute en la calidad final del producto. Otro aspecto de esta mala prensa es que el número de copias que se distribuyen es mínimo y 
que el público no está educado para ver ficción nacional, prefiriendo las películas animadas de procedencia norteamericana que son las que más publicidad y marketing realizan.

Sin embargo esto tiene visos de mejorar, así en el Semana de la Comunicación y la Creatividad organizada por la Universidad Europea de Madrid en abril de 2009 y dentro del Aula Europea de Animación se presentaron las conclusiones del informe "El cine de animación no americano (2000-2008)” promovido por la propia universidad y realizado por Pau Brunet ${ }^{8}$. En él se hace una comparación entre el cine de animación, tanto infantil como adulto, y el cine de imagen real. Además se detalla el impacto que las películas de animación han alcanzado durante ese periodo teniendo en cuenta que la mitad de las que se han exhibido en España proceden del mercado americano y sólo el veintitrés por ciento tenían origen en nuestro país.

Los resultados son sorprendentes pues llega a la conclusión de que las producciones animadas españolas y europeas tienen más aceptación que las de imagen real, ya que los estrenos duran más en cartel y las ventas internacionales son mucho más fructíferas. Los datos son contundentes ya que el promedio de recaudación de las películas españolas de animación en los últimos dos años es de 0,77 millones de euros, frente a 0,53 millones de los títulos de imagen real. Además, el cuarenta y cinco por ciento de los títulos animados superan el millón de euros, frente al diecisiete por ciento de imagen real.

La clave que explica esta superioridad económica es el distinto comportamiento del público ante la cartelera. Éste suele acudir de forma mucho más escalonada a ver cine cuando es de animación, así los primeros fines de semana suelen ser algo flojos de espectadores pero las cifras se van multiplicando más rápido conforme van pasando los días. Este hecho demuestra que pese a los escasos resultados que producen en su estreno, los descensos durante las siguientes semanas no son pronunciados lo que provoca que las cantidades finales de recaudación sean importantes. A diferencia de otros géneros, la animación, y el cine familiar en general, tiene mayor aceptación y facilidad a la hora de ser recomendado (lo que se conoce como boca a boca) y suele tener un amplio recorrido en las carteleras.

El informe de la Universidad Europea de Madrid, ya citado, destaca que entre el 20002008 los productos europeos y las co-producciones con España son los que mejores resultados han presentado. En el caso de las grandes apuestas de cine europeo (Valiant, Arthur y los Minimoys, El tiovivo mágico o Érase una vez...un cuento al revés) los 
comportamientos medios han estado sobre las seis veces su cifra inicial, mientras que en el caso de las co-producción con España (Pérez, el ratoncito de los sueños o Sueño de una noche de San Juan) han sido de cinco con cinco. En todos ellos se trata de lanzamientos fuertes, con más de ciento ochenta copias y unas promociones importantes. Con estos datos, no es extraño que España se haya convertido en uno de los tres mercados principales de Europa en los que más se producen películas animadas.

Es durante los primeros años de vida del menor cuando se les puede empezar educar, guiar en materia audiovisual y hacerlos responsables de sus opiniones, ya que el espectador de cine de animación infantil aún no tiene desarrollado el gusto por un determinado producto y el poder selectivo. A estas edades se limita a absorber las imágenes y analizarlas en busca de respuestas sencillas. Es aquí donde la labor de los tutores es imprescindible ya que son los adultos los que deben intervenir para seleccionar las obras que ayuden al correcto desarrollo del menor en todos los aspectos (psicológico, educativo, relacional, afectivo,...). Educar sobre las influencias que sobre ellos tienen los medios debe realizarse a través de estrategias didácticas que, integradas de forma curricular en su plan de estudios, les informen sobre el uso y consumo adecuado de productos mediáticos. Aunque al final la forma de enfrentarse a los medios sea una opción personal de cada uno.

Partiendo de esta premisa, mi visión de este cine no es tan alarmista ni catastrofista como la expuesta anteriormente. Es más, lo considero un instrumento único para educar ya que en él convergen los más diversos géneros y permite presentar una amplia gama de temas, historias, problemáticas y mensajes muy diversos pero que llegan fácilmente al público infantil.

Para el trabajo en Primaria debe prestarse una atención prioritaria a los personajes ya que este alumnado centra su interés más en ellos que en cualquier otra particularidad de la obra, y resultan unos elementos especialmente influenciables por las actitudes que muestran a lo largo de las historias. Las tareas deben dirigirse a la descripción y análisis de las características físicas, ropajes e indumentarias, expresiones corporales y su posible asociación a rasgos psicológicos o morales.

Los objetivos planteados para esta etapa podrían ser:

a) Competencia lingüística 
o Promover el diálogo entre el alumnado para que les sea más fácil expresar sus pensamientos, emociones, vivencias y opiniones.

o Utilizar la comunicación como elemento principal para la resolución pacífica de sus conflictos diarios.

b) Competencia en el conocimiento y la interacción con el mundo físico

o Mejorar el conocimiento de los alumnos sobre el mundo y la realidad sociocultural en la que viven.

o Fomentar las destrezas y habilidades sociales.

c) El tratamiento de la información y la competencia digital

o Empleo de Internet para buscar información

o Reconocer elementos del lenguaje audiovisual: planos, encuadres, secuencias, etc.

d) Competencia social y ciudadana

o Desarrollar destrezas y habilidades como la sensibilidad cultural, la superación de malentendidos y estereotipos, etc.

o Reconocer actitudes y valores tanto propios como del grupo.

o Identificar los personajes asociándolos a factores psicológicos y tipologías sociales de carácter estereotipado.

e) Competencia cultural y artística

o Valorar el sentido artístico del cine en general y el de animación en particular.

Con respecto a uno de los objetivos que pretendía alcanzar en este trabajo, el de analizar si los valores presentes en las obras se corresponden con los propuestos por la Consejería de Educación de la Junta de Andalucía de obligatoria enseñanza en las escuelas, se puede determinar que sin lugar a dudas tres son los valores que más se repiten en las películas analizadas. El primero de ellos es la educación para la paz y la interculturalidad, que se ha agrupado dentro de multiculturalidad, convivencia pacífica, tolerancia a las opiniones diferentes, aceptación de otras razas y culturas; el segundo e igualmente importante sería la educación para la participación activa en la sociedad y para la vida en comunidad que se considera presente en las actuaciones que llevan a 
cabo los personajes con un fin positivo y para solucionar problemas que les afectan tanto a ellos como a los de su alrededor. Por último, el tercero en importancia es la educación para el desarrollo y la cooperación que tiene mucho que ver con el anterior ya que en las tramas siempre hay mucho de cooperación, ayuda y amistad por parte de los protagonistas. Partiendo de la tabla de valores de la Junta de Andalucía su presencia sería la siguiente dentro de las películas:

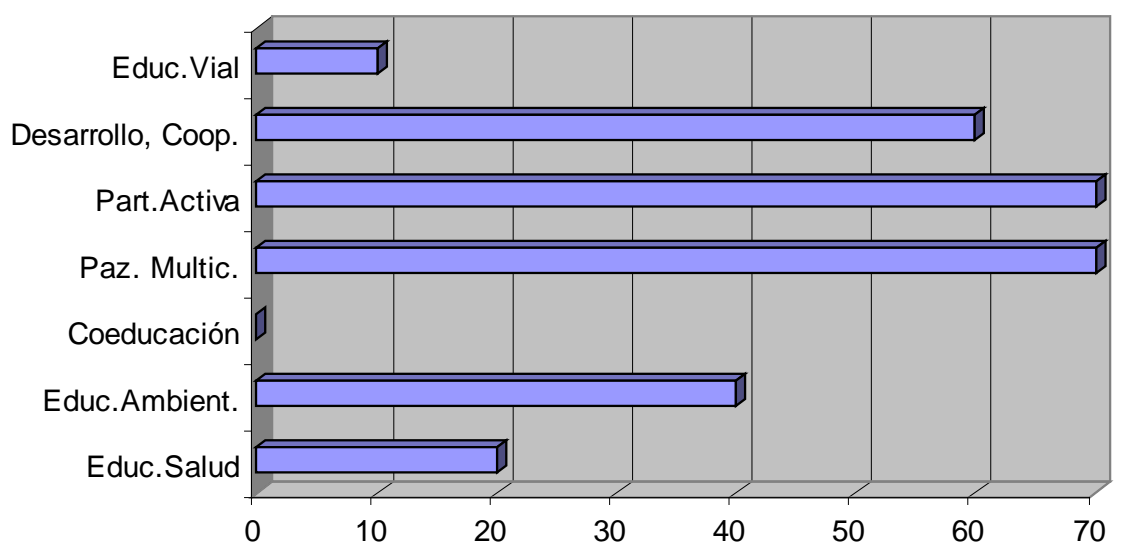

El término coeducación es definido en el Diccionario de la Real Academia de la Lengua Española como “educación que se da juntamente a jóvenes de ambos sexos”, es la educación que tiene en cuenta la formación de niñas y niños basada en los principios de igualdad de derechos y oportunidades superando así las desigualdades de género. Y aunque la igualdad de géneros es algo que está presente en prácticamente todas las películas ya que los personajes masculinos y femeninos tienen los mismos derechos y deberes, a la coeducación como tal no se la nombra ni se la tiene presente. La igualdad es algo implícito y asumido en las tramas, y quizás en estas edades los menores aún no son conscientes de las luchas de género ni las diferencias entre sexos es más, como añado más abajo, el que en principio se considera el héroe y salvador de la dama en apuros al final actúa más como antihéroe provocando toda clase de problemas y tropiezos. Por esta razón no se considera que el valor de la coeducación esté presente en ninguna de las películas porque es algo que está implícito en todas ellas.

Al contrario de lo que expone Granado (2002: 133-136) al analizar en su tesis doctoral las posibilidades que tienen las películas de Disney para ser trabajadas en la escuela y donde se nos descubre un amplio abanico de contravalores susceptibles de ser Admira $n^{\circ} 2$ - 2010 
enseñados a los menores, las películas españolas de animación no incurren de manera clara en asignar a los personajes femeninos roles sexistas, algo que el autor insiste en que es usual en el cine norteamericano. Según él en estas películas, los roles que se le asignan a la mujer son mínimos y cuando aparecen están fuertemente estereotipadas y con un gran reflejo de sometimiento y de mantenimiento de las buenas normas y conductas sociales establecidas.

En el caso del rol femenino, incluso cuando se quiere dar la impresión contraria para eliminar cierto sabor tradicionalista de las películas de esta factoría, tiende a reflejar el papel tradicional siempre asignado a la mujer y se nos descubren como abnegadas madres, solícitas esposas y buenas hijas; algo que no está tan claramente definido en el cine español analizado. Sobre todo a partir del año 2000 las películas españolas han evolucionado en las cuestiones de género y presentan a los personajes femeninos como compañeras de aventuras más que como conquistas amorosas. Esto no quita que en la mayoría de los casos, al inicio de la narración, los personajes femeninos se encuentran en apuros y deben ser salvadas por el héroe. Éste, que suele actuar torpemente metiéndose en continuos líos, no acaba consiguiendo su propósito y la víctima se convierte al final en heroína (El embrujo del sur, El bosque animado o El lince perdido).

El cine español fomenta actitudes como el respeto a la familia, la ayuda desinteresada, la aceptación de otras culturas y la importancia de la amistad. Genera beneficios medioambientales y rechaza los estereotipos sexistas y racistas que tanto condicionan nuestra manera de ver el mundo y de interaccionar en él. Por esta razón, y después de los análisis realizados, creo que oferta un material cuya rentabilidad educativa puede ser extraordinariamente potente para desarrollar tales propósitos.

Con todo lo anterior, está suficientemente atestiguada la potencialidad del cine, desde sus comienzos, como elemento transmisor de conceptos, valores y pautas de conducta. $\mathrm{Y}$ algo que ya se ha dicho en páginas precedentes, parece innegable su influencia sobre los valores y contravalores que predominan en una sociedad. Por ello, se considera que los valores latentes en la realidad actual se deben reflejar también en los filmes destinados a la infancia para que puedan leerlos a través de los diálogos y de las imágenes.

De ahí la convicción de que el cine, y el audiovisual en general, es el gran educador social por excelencia. Sin aulas, sin horario establecido, sin materias previamente Admira $n^{\circ} 2$ - 2010 
fijadas, en definitiva, educar sin ningún tipo de presión o formalidad. Así constantemente, determinadas películas están impartiendo educación moral a un alumnado que recibe su mensaje, las más de las veces, sin ninguna pretensión de recibir una formación precisa. Y resulta difícil de explicar que, existiendo instrumentos tan valiosos, estas obras cinematográficas no se utilicen más en educación social.

Por último sólo me queda añadir que este estudio ha tratado de demostrar los beneficios sociales que reporta el cine y la necesidad de una formación cinematográfica en educación primaria. La posibilidad de combinar cine y educación social dentro de lo que se conoce como educación no formal ${ }^{9}$ supone abarcar una serie de ámbitos de actuación educativa (alfabetización, educación durante el tiempo de ocio, educación para el consumo, educación para la salud, educación ambiental, animación sociocultural e intercultural, educar para los derechos humanos, medios de comunicación y desarrollo humano, etc.) que permiten hacer realidad aquel principio de que la educación es una tarea que prosigue incluso después de la escuela y que afecta a todos los estamentos sociales. Capacitar audiovisualmente al menor implica que al recibir un mensaje éste lo comprenda, lo descifre y pueda interpretar correctamente lo que otros han querido expresar.

Así, la riqueza y la calidad de la recepción de ese mensaje dependerán no sólo de la intención del emisor y de las características del mensaje sino también de la capacidad y formación para la lectura audiovisual del receptor-espectador. En definitiva se persigue la adopción de conocimientos, habilidades y capacidades que permitan desarrollar estrategias que ayuden a interpretar el significado que conlleva el mensaje.

Por eso se aboga por la idea de concebir el cine no sólo como un medio de comunicación más, sino como un apoyo pedagógico permanente en los procesos de aprendizaje del alumnado ya que promueve el desarrollo de habilidades sociales, además de predisponer a la reflexión, al análisis y al juicio crítico, a crear y a transmitir actitudes y valores sociales y culturales (Platas, 1994).

\section{Notas}

\footnotetext{
${ }^{1}$ Mediante un convenio entre los Ministerios de Trabajo y Asuntos Sociales, Educación y Ciencia; y a través del Instituto de la Mujer y del Centro de Investigación y Documentación Educativa (CIDE) se han publicado siete cuadernos de educación en valores bajo el título Por preguntar que no quede.
} 
${ }^{2}$ Con sus publicaciones Plan de Interculturalidad para Cantabria (2005) y Plan para la convivencia en los centros escolares de Cantabria (2005).

${ }^{3}$ La educación en valores en Castilla-La Mancha tiene como objetivo la formación de ciudadanos y ciudadanas críticos que participen activamente en la construcción de un mundo más combativo contra todo tipo de discriminaciones, más saludable y más $\begin{array}{lllll}\text { respetuoso } & \text { con medio ambiente. }\end{array}$ Se rige por el Decreto 164/2002, de 19/11/2002, por el que se regula la coordinación de la distintas Consejerías de la Junta de Comunidades de Castilla-La Mancha en materia de educación en valores.

${ }^{4}$ La Junta de Extremadura ha creado el CD Participación Joven con materiales para trabajar los valores en la Enseñanza Secundaria, sobre todo en el área de educación para la ciudadanía y los derechos humanos.

${ }^{5}$ Películas analizadas en el proyecto de investigación original:

Marco Antonio rescate en Hong Kong (2000)

El bosque animado (2001)

El embrujo del sur (2003)

Pérez, el ratoncito de tus sueños (2006)

Gisaku (2006)

Donkey Xote (2007)

Nocturna, una aventura mágica (2007)

De Profundis (2007)

El espíritu del bosque (2008)

El lince perdido (2008)

${ }^{6}$ La era de la comunicación visual ha supuesto que desde la pantalla de un ordenador se pueda acceder a un medio mucho más potente que la televisión ya que utiliza una amplia red de comunicación e información basada en estructuras visuales (imagen), se trata de Internet.

${ }^{7}$ Se denominan transversales aquellos temas que están presentes de forma global en los contenidos y objetivos de todas las áreas educativas, sin corresponder de manera exclusivo a ninguna de ellas. Las características pedagógicas más importantes de estos temas son:

- Se integran en el currículo y deben estar presentes en el Proyecto Educativo de Centro. 
- Constituyen ejes de contenidos, objetivos y principios relacionados con los valores y las actitudes que el propio centro tiene como objeto fomentar.

- Se desarrollan en todas las áreas curriculares. Como parte de ellas.

- Son responsabilidad de toda la Comunidad Educativa.

- Poseen una flexibilidad que no tienen otras materias para su programación.

- Abordan problemáticas sociales que se relacionan de forma directa con las propias experiencias vitales del alumno.

${ }^{8}$ Analista de mercados cinematográficos y creador del la web BoxOffice.

${ }^{9}$ Educación no formal es toda actividad organizada, sistemática, educativa, realizada fuera del marco del sistema oficial, para facilitar determinadas clases de aprendizaje a subgrupos particulares de la población, tanto adultos como niños (Vázquez, 1998: 12).

\section{Referencias bibliográficas}

Aguaded. J.I. (2003). Una gran pantalla para la educación: el cine en las aulas en Making of: Cuadernos de cine y educación n 19, pp.63-66.

Almacellas, M. A. (2004). Educar con el cine. Madrid, Ediciones Internacionales Universitarias.

Amar, V.M. (2003). Cine y educación: un juego de seducción en Making of: Cuadernos de cine y educación $n^{\circ}$ 18, pp.63-68.

Ambrós, A. \& Breu, R. (2007). Cine y educación: el cine en el aula de primaria y secundaria. Barcelona, Graó.

Bergala, A. (2007). La hipótesis del cine: pequeño tratado sobre la transmisión del cine en la escuela y fuera de ella. Barcelona, Laertes.

Bonilla, J. (2005). El cine y los valores educativos. A la búsqueda de una herramienta eficaz de formación en Píxel-Bit: Revista de medios y educación no 26 pp.39-54. Sevilla, Universidad de Sevilla.

Buckingham, D. (2005). Educación en medios: Alfabetización, aprendizaje y cultura contemporánea. Barcelona, Paidós.

Carmona, R. (1993). Cómo se comenta un texto fílmico. Madrid, Cátedra Signo e Imagen. 
Casals, E. (2005). La importancia de trabajar los valores en la educación infantil en Casals, E \& Delfis, O. (Eds.). Educación infantil y valores. Bilbao, Desclée De Brouwer.

Casetti, F. \& Di Chio, F. (1991). Cómo analizar un film. Barcelona, Paidós.

De la torre, S.; Pujol, M.A. \& Rajadell, N. (2005). El cine, un entorno educativo: diez años de experiencias a través del cine. Madrid, Narcea.

Equipo padres y maestros (2009). Cine y Ciudadanía. Valores para trabajar en el aula. Bilbao, Mensajero.

Espada, A. (2001). Guía de educación en valores. Sevilla, Consejo de la Juventud de Andalucía, Consejería de Educación y Ciencia.

Fontcuberta, M. (2001). El rol de los medios de comunicación en la gestión del conocimiento, en Crovi, D. (Ed.) Comunicación y Educación: La perspectiva latinoamericana. México D.F., ILCE, pp. 57-71.

Gabelas, J.A. (2007). Una perspectiva de la educación en medios para la comunicación en España en Comunicar: Revista científica iberoamericana de comunicación y educación nº 28, pp. 69-73.

Galiano, M. (2007). Interculturalidad y coeducación en el cine de animación. Granada, II Jornadas Internacionales sobre políticas educativas para la sociedad del conocimiento.

Gómez, J. (2003). Educar en nuevas tecnologías y medios de comunicación. Vol. 1 La educación en una sociedad tecno-mediática: Integración de las nuevas tecnologías y medios de comunicación en los contextos educativos. Badajoz, F.E.P. (Fondo de educación y promoción de Caja Rural de Extremadura).

Granado, M. (2002). Disney en la escuela. Cádiz, Tesis Doctoral Facultad de Educación de la Universidad de Cádiz, 2 vols.

Gutiérrez, M ${ }^{a}$ C.; Pereira, M $M^{a}$ C. \& Valero, L. F. (2006). El cine como instrumento de alfabetización emocional en Teoría de la Educación. Revista Interuniversitaria, vol. 18, pp. 229-260.

Kaplún, M. (1998). Una pedagogía de la comunicación. Madrid, Ediciones de la Torre.

León, J.L. (1988). La investigación en publicidad. Bilbao, Universidad del País Vasco. 
López, J.S. \& Scandroglio, B. (2007). De la investigación a la intervención psicosocial: la metodología cualitativa y su integración con la metodología cuantitativa en Blanco, A.\& Rodríguez, J. (coord). Intervención psicosocial. Madrid, Pearson.

Pereira, C. (2005). Los valores del cine de animación. Propuesta pedagógica para padres y educadores. Barcelona, PPU.

Pereira, C. (2005). Cine y educación social en Revista de Educación n 338, pp. 205228.

Pérez Tornero, J.M. (comp.) (2000). Comunicación y educación en la sociedad de la información. Barcelona, Paidós.

Platas, A. M (coord.) (1994). Literatura, cine, sociedad. La Coruña, Tambre.

Pérez Tornero, J.M. (2007). La sociedad multipantallas: retos para la alfabetización mediática en Comunicar: Revista científica iberoamericana de comunicación y educación, $n^{0}$ 31, pp. 15-25.

Prats, LL. (2005). Cine para educar. Guía de más de 200 películas con valores. Barcelona, Belacqva de ediciones y publicaciones.

Savater, F. (2004). El valor de educar. Barcelona, Ariel.

Serra, J. (1970). Cine formativo. Barcelona, Nova Terra.

Vázquez, G. (1998). Educación no formal y otros contextos próximos, en Sarramona, J.;

Vázquez, G. \& Colom, A. J. (Eds.). Educación no formal. Barcelona, Ariel. 